\title{
Polymorphs related by enantiotropic phase transition but having only order-disorder-level conformational difference in a spiro-conjugated imidazolidine ring compound
}

\author{
Mitsuaki Suzuki, ${ }^{\text {a }}$ Yutaka Maeda ${ }^{a}$, Motoko Akita, ${ }^{\text {b }}$ Hiroyuki Teramae, ${ }^{\text {b }}$ and Keiji \\ Kobayashi $^{\text {b* }}$ \\ a Department of Chemistry, Tokyo Gakugei University, Koganei, Tokyo 184-8501, \\ Japan \\ ${ }^{\mathrm{b}}$ Graduate School of Material Science, Josai University, Sakado, Saitama 350-0295, \\ Japan
}

\begin{abstract}
Variable-temperature single-crystal X-ray diffraction analyses of 1,3diethyl-spiro[imidazolidine-2,2'-[2H]indene]-1',3'-dione (1) were performed at low temperatures. The temperature dependence of the cell parameters exhibited a discontinuous change between 158 and $153 \mathrm{~K}$, indicating the existence of a phase transition and hence the occurrence of two polymorphs I and II, which was also confirmed by DSC analysis: reversible exothermic and endothermic peaks with $\Delta H=$ $2.1 \mathrm{~kJ} / \mathrm{mol}$ were observed in the cooling and heating processes, respectively. The molecular packing in I and II at $200 \mathrm{~K}$ and $90 \mathrm{~K}$, respectively, remained essentially unchanged keeping the space group Pnma. I and II are conformationally isomorphic crystals, including two crystallographically independent molecules, $\mathbf{A}$ and $\mathbf{B}$, with different conformations in a 1:2 ratio. Upon the phase transition from I to II with decreasing temperature, the dynamic disorder of the imidazolidine ring of $\mathbf{A}$ in $\mathbf{I}$, which interconverts between quasi-half-chair conformations, is frozen to settle in an envelope conformation, while $\mathbf{B}$ is retained in a half-chair conformation in both $\mathbf{I}$ and II. The close intermolecular contacts in I and II were compared on the basis of Hirshfeld surface analysis. DFT calculations at the B3LYP/6-311G(d,p) level show that the half-chair structure is more stable than the envelope conformer by $2.6 \mathrm{~kJ} / \mathrm{mol}$ in the gas phase. The quasi-half-chair conformation was not obtained as an energy-minimum geometry on the potential energy surface. Temperature-dependent IR spectroscopy along with theoretical calculation using the QST method gave assignments of the carbonyl stretching bands for each conformation. Compound $\mathbf{1}$ provides a unique
\end{abstract}


example of the isostructural polymorphs in which the structural differences are small, being only at the order-disorder level in the ring conformation; nevertheless, the existence of the enantiotropic phase transition clearly indicates that they are polymorphs.

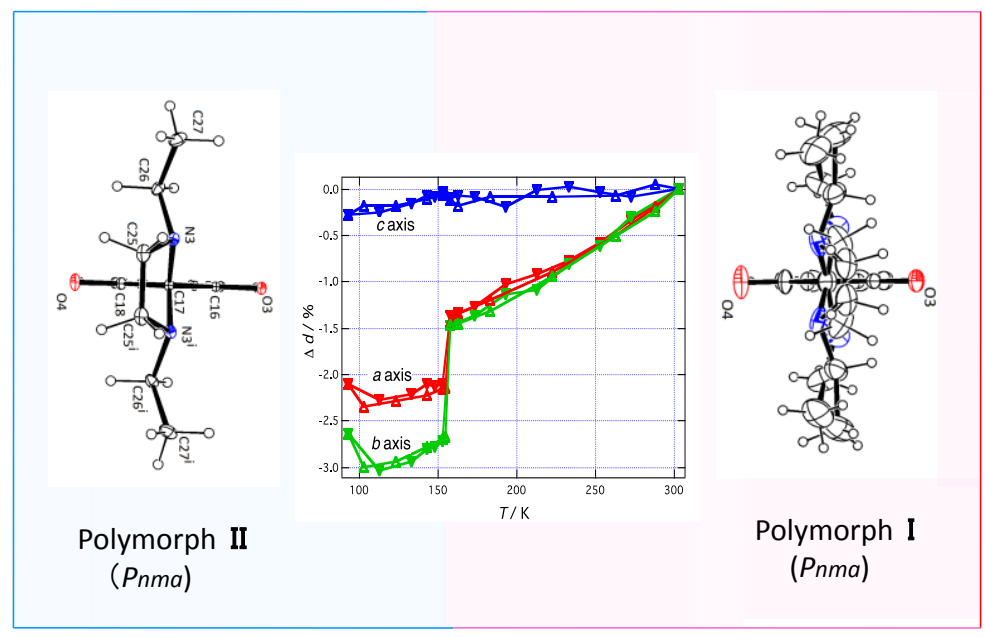

\section{Introduction}

The order-disorder-type phase transitions triggered by the reorientation or displacement of molecules in the crystalline lattice of organic crystals are well known to occur in globular-shaped molecules or discotic planar molecules as well as in one-dimensional arrays of molecular units. More recently, in the design of molecular ferroelectric transitions, supramolecular complexes such as crown ethers, cage-type compounds, and metal-organic frameworks have been extensively investigated as a tool for controlling molecular motion in crystalline lattices. ${ }^{1}$ Such order-disorder phase transitions are usually associated with a change in the space group of the crystalline phases by ordering to more stable molecular packing on cooling. On the other hand, the phase transitions triggered by conformational order-disorder appear to have attracted less interest apart from those for dynamics of polymer chain, although a number of 
crystals including conformational disorder, either statically multiple-populated or dynamically equilibrated, are known. The paucity of phase transitions in conformationally disordered crystals ${ }^{2}$ can be understood by considering that conformers populated at higher temperatures are continuously converted with decreasing temperature to crystalline variations including a lower degree of disorder, reaching an equilibrium state or freezing in a single stable conformation. ${ }^{3}$ Because the conformational change is caused only in parts of the molecular structure, the original crystal structures can remain almost unchanged, ${ }^{4}$ maintaining the same space group of the crystal lattice with only a slight decrease in the cell parameters. Such variations of crystals can be referred to as conformationally disordered crystals. ${ }^{5}$ On the other hand, when a reversible transition temperature is observed between the conformational order and disorder phases, these crystals can be regarded as conformational polymorphs ${ }^{6}$ because of the existence of distinct multiple solid phases. It is also reasonable to characterize such polymorphs as enantiotropic polymorphs, ${ }^{7}$ wherein, at a certain temperature, two polymorphs are in equilibrium and each has its own range of stability and crystal structures. Then, in view of the conformational variation in the crystalline state, where is the borderline between a polymorph and disorder? In relation to this issue, ${ }^{8}$ we demonstrate herein a peculiar case of polymorphs, which are enantiotropic polymorphs judging from the existence of the first-order phase transition. Nevertheless, their crystal structures include only order-disorder-level alterations, exhibiting a slight change in the crystal lattices without a change in the space group, making them appear to be a variation of conformationally disordered crystals.

The phase transition in question has been found in crystals of 1,3diethyl-spiro[imidazolidine-2,2'-[2H]indene]-1',3'-dione (1). ${ }^{9}$ This family of spiro- $N, N$-ketals exhibits a red color despite the absence of expanded $\pi$-conjugation. The color is ascribable to an intramolecular charge-transfer transition via spiro- $\pi$-conjugation, ${ }^{10}$ while in $\mathbf{1}$ the donor side bears no $\pi$-electrons but only n-electrons on the nitrogen atoms and hence its color is considered to be due to $\mathrm{n}-\pi^{*}$ spiro-conjugation. The X-ray crystal structure of $N, N$-diphenyl derivative $\mathbf{2}$ has been reported. ${ }^{11}$ In this context, we performed the X-ray analysis of the crystal structure of $\mathbf{1}$ in comparison with that of $\mathbf{2}$ and was led to find the phase transition in $\mathbf{1}$. 


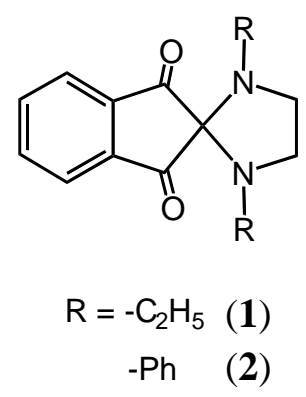

Scheme 1. Molecular structures of $\mathbf{1}$ and 2.

\section{Experimental}

\section{Sample Preparation}

Compound 1 was prepared according to a procedure reported in the literature. ${ }^{9}$ Block red crystals with a melting point of $98{ }^{\circ} \mathrm{C}$ were obtained by dissolving $\mathbf{1}$ in a minimum amount of acetonitrile. The solution was left to evaporate slowly, and crystals were obtained after 5-7 days.

\section{X-ray Diffraction Analysis}

The temperature dependence of cell parameters was determined on a Rigaku RAXIS RAPID imaging plate area detector with graphite monochromated Mo- $K \alpha$ radiation $(\lambda=$ $0.71075 \AA$ A). A red block crystal having approximate dimensions of $0.40 \mathrm{x} 0.40 \mathrm{x} 0.20$ $\mathrm{mm}$ was mounted on a glass fiber. Indexing was performed from three oscillations $\left(\omega=0^{\circ}, 90^{\circ}, 180^{\circ}\right)$ that were exposed for 10 seconds. The crystal-to-detector distance was $127.40 \mathrm{~mm}$. The data were initially collected at $303 \mathrm{~K}$ and decreasing the temperature down to $93 \mathrm{~K}$, while the low temperature data set was measured at intervals of 10-20 K. Then, temperature was increased back to $303 \mathrm{~K}$. Cooling and heating rates were $5 \mathrm{~K} / \mathrm{min}$. The numerical data are listed in Table S1.

Single-crystal X-ray diffraction data were collected at $90 \mathrm{~K}, 120 \mathrm{~K}, 160 \mathrm{~K}$, and 200 $\mathrm{K}$ on a Bruker SMART APEX II diffractometer equipped with a CCD area detector using MoK $\alpha$ radiation $(\lambda=0.71073 \AA$ ). The multiscan method was used for absorption corrections. The structures were resolved by direct methods with SHELXL-97 and refined by the full-matrix least-squares on $F_{2}$ with SHELXL-2014. ${ }^{12}$ All C, O, and $\mathrm{N}$ atoms were refined anisotropically. For the data at $90 \mathrm{~K}$ and $120 \mathrm{~K}$, all hydrogen atoms were added from the difference Fourier map and refined with a riding model. For the data at $160 \mathrm{~K}$, hydrogen atoms were added from the difference 
Fourier map or using the HFIX command and refined with a riding model. For the data at $200 \mathrm{~K}$, all hydrogen atoms were added geometrically (using the HFIX command) and refined with a riding model. The atoms of the disordered part were refined with 0.50 occupancies. The disorder was treated anisotropically with SIMU and was fixed by the DFIX command. The crystallographic data and the final refinement at $90 \mathrm{~K}, 120 \mathrm{~K}, 160 \mathrm{~K}$, and $200 \mathrm{~K}$ are shown in Table 1. X-ray crystallographic information files (CIF) of compounds $\mathbf{1}$ is available free of charge via the Internet athttp://pubs.acs.org. Crystallographic information files are also available from the Cambridge Crystallographic Data Center(CCDC) upon request (http://www.ccdc.cam.ac.uk, CCDC).

Molecular Hirshfeld surfaces in the crystal structure were constructed basing on the electron distribution calculated as the sum of spherical atom electron densities. Hirshfeld surfaces were produced with program Crystal Explorer (version 3.1). ${ }^{13}$ The surfaces were produced displaying the normalized contact distance $d_{\text {norm }}$ in a red-white-blue color scheme, ${ }^{14}$ where red highlights contacts shorter than the sum of van der Waals radii, white is used for contacts around the vdW separation, and blue is for longer contacts. The 2D fingerprint plots were generated based on both $d_{e}$ and $d_{i}$ and the vdW radii of the atom, wherein $d_{e}$ and $d_{i}$ are distances to the nearest atoms outside and inside of the surface, respectively.

Table 1. Crystal data and structure refinement for 1 at $90 \mathrm{~K}, 120 \mathrm{~K}, 160 \mathrm{~K}$, and $200 \mathrm{~K}$.

\section{Thermal Analysis}

DSC analysis was performed on an X-DSC7000 system (SII nanotechnology) in the temperature range from $220 \mathrm{~K}$ to $120 \mathrm{~K}$ at cooling and heating rates of $2 \mathrm{~K} / \mathrm{min}$. Aluminum sample pans with crimped but vented lids were used under nitrogen atmosphere. Aluminum disk was used as reference. A $30 \mathrm{~mL} / \mathrm{min}$ nitrogen purge was employed. The measurements were carried out twice using $9.806 \mathrm{mg}$ and 5.086 $\mathrm{mg}$ of polycrystalline sample for the first and second run, respectively. The results were in fair agreement with each other.

\section{FT-IR Analysis}

Temperature-dependent FT-IR spectra were recorded on a JASCO FT/IR-6100 FT-IR spectrometer equipped with an IR microscope (IRT-5000 IR) for samples slightly 
compressed on $\mathrm{BaF}_{2}$ disks. The temperature was lowered at $5 \mathrm{~K} / \mathrm{min}$ from room temperature to $133 \mathrm{~K}$, being held constant at $243 \mathrm{~K}, 223 \mathrm{~K}, 193 \mathrm{~K}, 183 \mathrm{~K}, 173 \mathrm{~K}, 153 \mathrm{~K}$, $143 \mathrm{~K}, 133 \mathrm{~K}$, while the spectrum at each temperature was recorded. Then, the sample was heated to room temperature without controlling the heating rate.

\section{DFT Calculations}

The calculations were carried out for $\mathbf{1}$ in the gas phase using the Gaussian 09 program. The geometry optimization and electronic structure determination were computed at the B3LYP/6-311G(d,p) level. The calculations were performed including the polarization functions for all atoms.

Since there are many conformers in $\mathbf{1}$, we first searched for conformers using the Hamiltonian algorithm, which has been shown to be significantly effective for finding local minima. ${ }^{15}$ The calculations with the Hamiltonian algorithm were performed at the HF/6-31G(d,p) level. Some optimized geometries with twist and envelope forms were obtained, which were further refined at the B3LYP/6-311G(d,p) level.

The transition state structure between the envelope and twist conformers was obtained at the B3LYP/6-311G(d,p) level using the QST2 method ${ }^{16,17}$ built in the Gaussian 09 program package. ${ }^{18}$ Vibrational frequency calculations were performed to confirm that the obtained optimized structure is the true transition state/minimum. All the calculations were performed using the Gaussian 09 program package.

\section{Results and Discussion}

\section{Crystal Structures in Low-Temperature Phase (polymorph II)}

Single crystals of $\mathbf{1}$ suited for X-ray crystallography were obtained by slow evaporation of the solvent from an acetonitrile solution of 1 . In the variable-temperature single-crystal X-ray diffraction analysis, the cell parameters change as shown in Figure 1. The lattice constants $a$ and $b$ decrease with decreasing temperature accompanied by a discontinuous change between 158 and $153 \mathrm{~K}$, while the $c$-axis scarcely changes. The discontinuous changes in the $a$-and $b$-axes are observed upon both increasing and decreasing the temperature. Thus, the crystals of $\mathbf{1}$ undergo a reversible phase transition at a low temperature and exist as two polymorphic forms, which is also supported by the results of DSC measurements and temperature-dependent IR spectral studies as described later. 


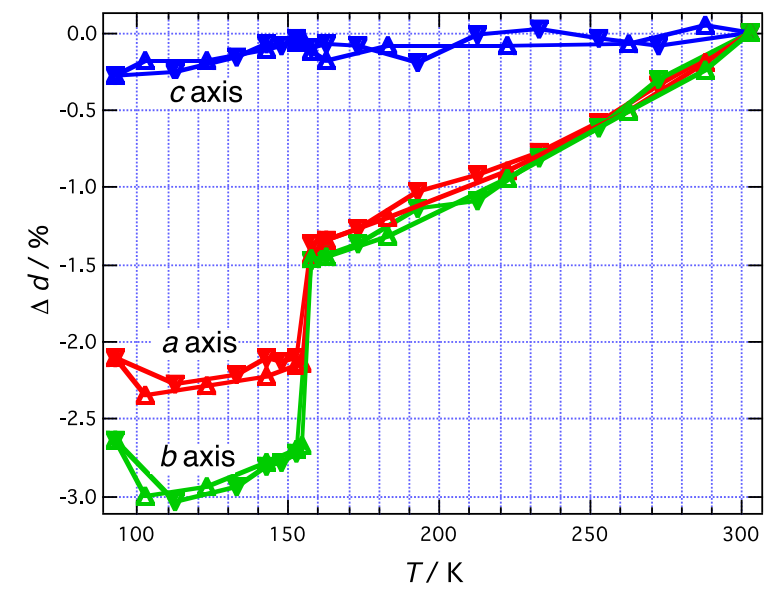

Figure 1. Temperature dependence of the cell parameters, showing the percent decrease from those at $300 \mathrm{~K} . \nabla$ : cooling. $\triangle$ : heating.

First, let us start with the crystal and molecular structures of $\mathbf{1}$ at $90 \mathrm{~K}$, i.e., polymorph II of the low-temperature crystalline phase. The crystal structure of $\mathbf{1}$ was also determined at $120 \mathrm{~K}$ and is essentially identical to polymorph II (Table 1). The crystal of II belongs to the orthorhombic system and has a centrosymmetric space group Pnma with 12 molecules in a unit cell. The unit cell contains two crystallographically independent molecules, $\mathbf{A}$ and $\mathbf{B}$, in a 1:2 ratio. One of the two independent molecules, $\mathbf{A}$, adopts an envelope conformation with respect to the imidazolidine ring to provide a molecular structure with Cs symmetry (Fig. 2b, Figure 3b), whereas the other, B, has a half-chair conformation with an approximate twofold rotation axis, making it close to having $C_{2}$ symmetry (Figure 2a, Figure 3c). Thus, I provides an example of conformational isomorphism, with more than one molecular conformer existing in the same crystal structure. ${ }^{6 b, 19}$ The molecular arrangements of $\mathbf{A}$ and $\mathbf{B}$ are shown in Figure 4. Molecule $\mathbf{A}$ is linearly aligned along the $a$-axis and also along the $c$-axis; it forms a layer in the $a c$-plane. Along the $a$-axis there are short intermolecular contacts between the carbonyl oxygen $(\mathrm{O} 4)$ and the peri-hydrogen of the 1,3-indandione

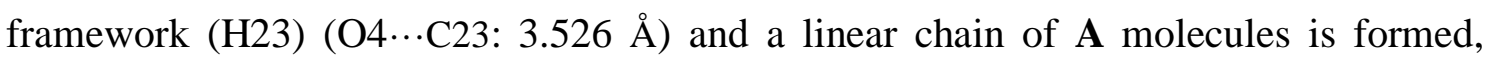
while along the $c$-axis there are no sequential intermolecular contacts. The other carbonyl oxygen (O3) of A links two $\mathbf{B}$ molecules by bifurcated short contacts with the peripheral hydrogen (H5 and H6) of the benzene ring in the 1,3-indandion unit of $\mathbf{B}$. Molecule $\mathbf{B}$ also forms layers in the $a c$-plane, which consist of two centrosymmetry-related molecules of $\mathbf{B}$ as a building unit and alternate with layers of $\mathbf{A}$ along the $b$-axis (Figure 4). 

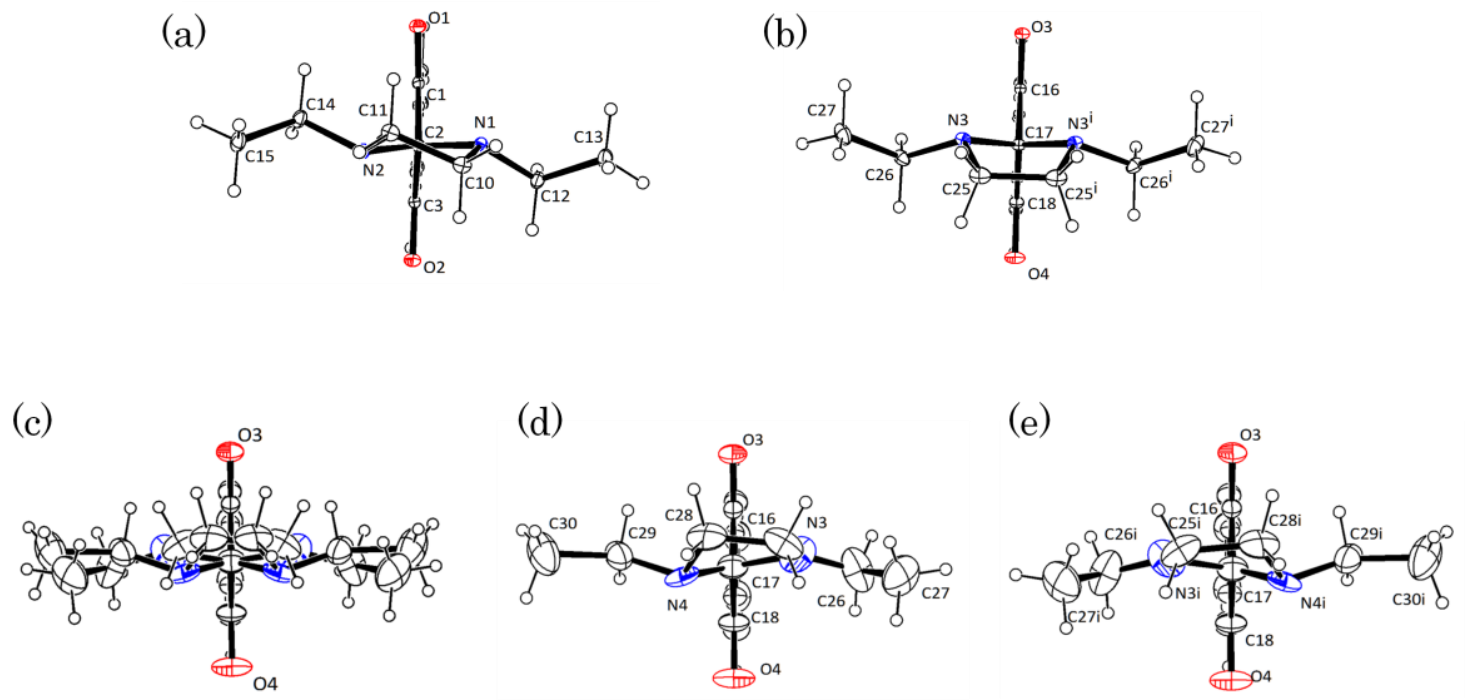

Figure 2. ORTEP drawings of temperature-dependent molecular structures for $\mathbf{A}$ and

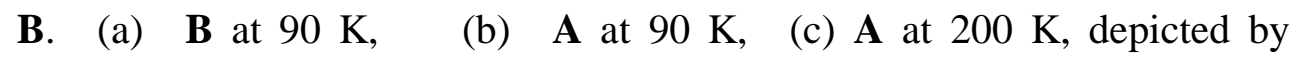
superimposition of disordered conformers, (d) and (e), in a 1:1 ratio. Ellipsoids represent atomic displacement parameters with $30 \%$ probability of finding the electron density of the atom.
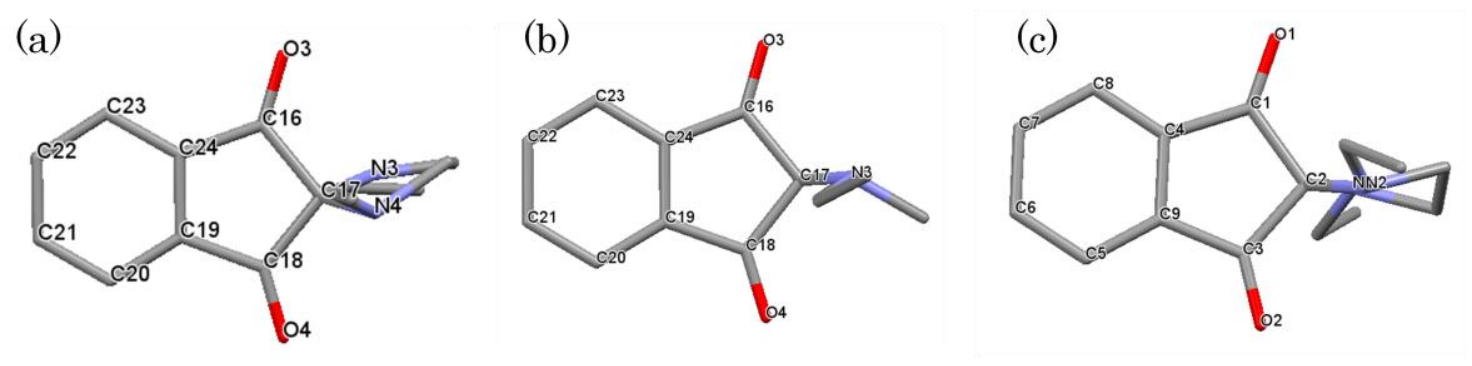

Figure 3. Side views of the imidazolidine ring of $\mathbf{1}$ represented by a capped sticks model to show conformational differences clearly. The hydrogen atoms are omitted for clarity. (a) Interconverting quasi-half-chair form of $\mathbf{A}$ in $\mathbf{I}$. (b) Envelope form of $\mathbf{A}$ in II. (c) Half-chair form of $\mathbf{B}$ in I and II. 


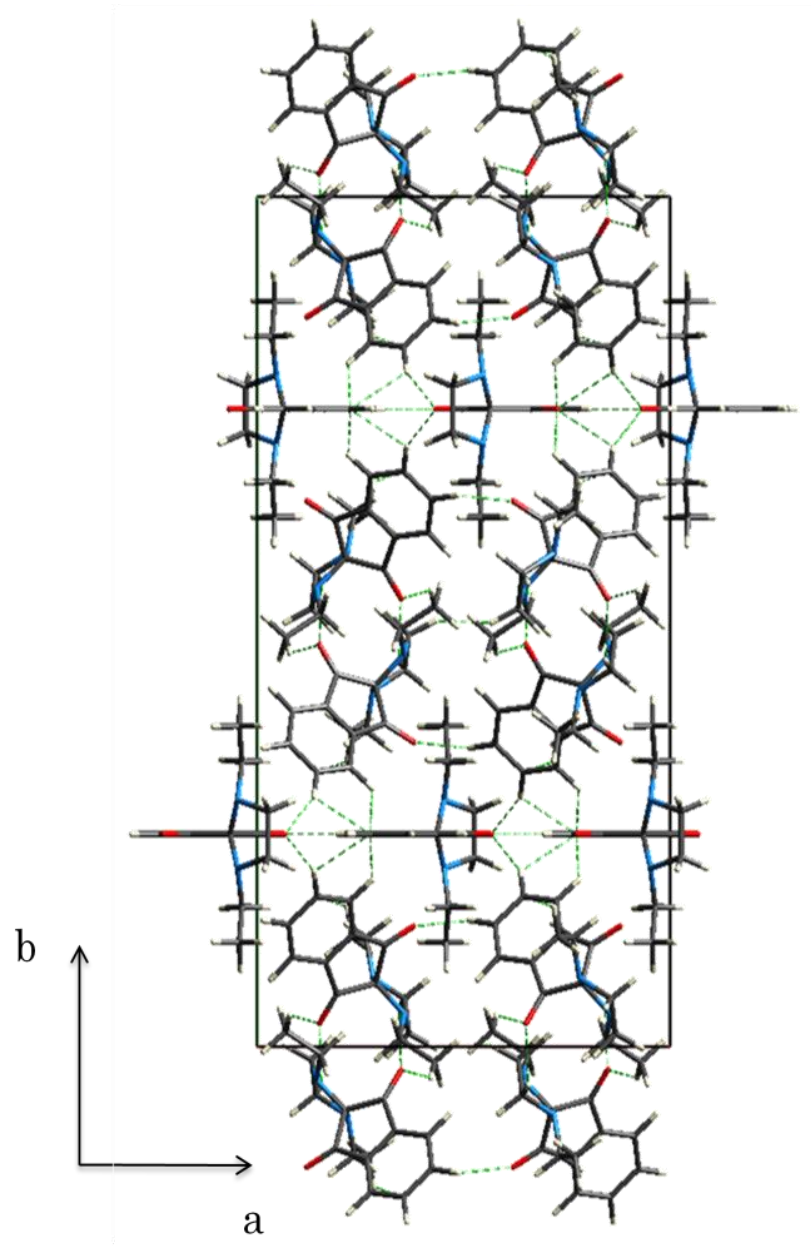

Figure 4. Crystal packing of $\mathbf{1}$ at $90 \mathrm{~K}$ viewed along the $c$-axis.

Selected bond distances, angles, and torsion angles at $90 \mathrm{~K}$ are listed in Table S2 (for A) and Table S3 (for $\mathbf{B}$ ). The angles related to the spiro carbon of the envelope form $\mathbf{A}$ are almost compatible with those of the half-chair form B: $\mathrm{C}-\mathrm{C}_{\text {spiro }}-\mathrm{C}: 102.9(1)^{\circ}$ and $\mathrm{N}-\mathrm{C}_{\text {spiro }}-\mathrm{N}: 103.7(1)^{\mathrm{o}}$ for $\mathbf{A}, \mathrm{C}_{-} \mathrm{C}_{\text {spiro }}-\mathrm{C}: 103.02(8)^{\circ}$ and $\mathrm{N}-\mathrm{C}_{\text {spiro }}-\mathrm{N}: 104.99(8)^{\circ}$ for $\mathbf{B}$. The $\mathrm{C}-\mathrm{N}-\mathrm{C}$ angles of the imidazolidine ring are $106-107^{\circ}$ for both $\mathbf{A}$ and $\mathbf{B}$, while the angles related to the endocyclic methylene of the ethyl group, $\mathrm{C}_{\text {spiro }}-\mathrm{N}-\underline{C}_{\mathrm{Et}}$, of $\mathbf{A}$ and $\mathbf{B}$ are more extended to $115^{\circ}-116^{\circ}$, forming the pyramidal geometry for the nitrogen with the sum of the valence angles equal to $337^{\circ}$ for $\mathbf{A}$ and $339^{\circ}$ for $\mathbf{B}$. For the imidazolidine ring of $\mathbf{B}$, the torsion angle $\mathrm{N}-\mathrm{C}-\mathrm{C}-\mathrm{N}$ is $43.6(1)^{\circ}$, close to that for a staggered conformation, implying that $\mathbf{B}$ exists as a half-chair form (Figure 2a). On the other hand, in $\mathbf{A}$, the corresponding torsion angle is $0.0(1)^{\mathrm{o}}$, since $\mathbf{A}$ is in an eclipsed conformation that forms an envelope form (Figure 2b). Regarding the lengths of the bonds constructing the imidazolidine rings in $\mathbf{A}$ and $\mathbf{B}$, the $\mathrm{C}-\mathrm{N}$ bonds are shorter than the $\mathrm{C}-\mathrm{C}$ bond. In 
particular, for molecule $\mathbf{A}$, the $\mathrm{C}_{\text {spiro }}-\mathrm{N}$ bond length is markedly shortened to 1.453(1) $\AA$. The conformation of the imidazolidine ring in $N, N$-diphenyl derivative 2 shows a significant difference from that of $1 ; 2$ crystallizes in space group $P-1$ with $\mathrm{Z}=2$ and its crystal system is triclinic, in which the molecule has neither approximate $C_{2}$ nor $C s$ symmetries and adopts an irregularly twisted conformation. ${ }^{11}$ Thus, one of the nitrogen atoms has an almost planar geometry while the other is pyramidal. The bond distances in $\mathbf{1}$, however, are comparable with those reported for the imidazolidine ring of $\mathbf{2}^{11}$ Because of the spiro-conjugation, the nitrogen atoms are positioned close to the carbonyl groups of the 1,3-indandione moiety. Thus, short intramolecular distances, which are within the sum of the van der Waals radii of nitrogen and oxygen, are observed for $\mathrm{N} \cdots \mathrm{O}$; 2.996(1) and 3.095(1) $\AA$ in A and 2.970(1) and 3.003(1) $\AA$ in B. Such a tight geometry would be advantageous for intramolecular charge-transfer excitation.

\section{Crystal Structures in High-Temperature Phase (polymorph I)}

The crystal structures of $\mathbf{1}$ were determined above the transition temperature at 160 $\mathrm{K}$ and $200 \mathrm{~K}$ for the high-temperature phase, polymorph $\mathbf{I}^{20}$ Above the transition temperature, because of the unusually large apparent thermal motion of $\mathbf{A}$, a difference Fourier map was investigated in detail and a disordered model was constructed, in which the $N, N$-diethylimidazolidine ring units are populated in a 1:1 ratio at the positions related by twofold rotation about the long molecular axis (Figure 2c). On the other hand, molecule $\mathbf{B}$ was not disordered and remained in its half-chair conformation at $200 \mathrm{~K}$ as well as at $90 \mathrm{~K}$. Thus, polymorph $\mathbf{I}$ essentially retains the molecular packing of polymorph II: I and II are isostructural with each other. Table S2 shows selected bond distances, angles, and torsion angles of molecule $\mathbf{A}$ in polymorph $\mathbf{I}$ at 160 $\mathrm{K}$ and $200 \mathrm{~K}$. For $\mathbf{B}$, the molecular geometries in polymorph $\mathbf{I}$ at $200 \mathrm{~K}$ are shown in Table S3 in comparison with those in polymorph II at $90 \mathrm{~K}$.

The disorder of $\mathbf{A}$ observed in polymorph $\mathbf{I}$ is due to the dynamic interconversion between the two equivalent quasi-half-chair conformations of the imidazolidine ring (Figure $2 \mathrm{~d}$ and $2 \mathrm{e}$ ), in which the $C s$ symmetry of the imidazolidine ring at $90 \mathrm{~K}$ is broken to force the two $\mathrm{C}_{\text {spiro }}-\mathrm{N}$ bonds and two $\mathrm{C}_{\text {spiro }}-\mathrm{N}-\mathrm{C}$ angles into an inequivalent geometry. The dynamic nature of the disorder of $\mathbf{A}$ can be evaluated from the temperature-dependent displacement of the nitrogen atoms and consequently the carbon atoms connected to these nitrogen atoms. Thus, with increasing temperature from 90 $\mathrm{K}$ to $200 \mathrm{~K}$, the distances between the nitrogen atoms, $\mathrm{N}(3) \cdots \mathrm{N}(4)$ and the carbon atoms, $\mathrm{C}(25) \cdots \mathrm{C}(28)$, are gradually increased up to $0.611 \AA$ and $0.621 \AA$, respectively (Table S2) and the thermal ellipsoids of the imidazolidine ring and the N-ethyl substituents 
become larger (Figure 2). The dynamic motion in I could be regarded as the puckering of a quasi-half-chair conformation, which is termed for distinction from the half-chair conformation of $\mathbf{B}$ (Figure 2 and Figure 3). In $\mathbf{B}$ the $\mathrm{N}-\mathrm{C}_{\text {spiro }}-\mathrm{N}$ plane and the $(\mathrm{O}=\mathrm{C})-\mathrm{C}_{\text {spiro }}-\mathrm{C}(=\mathrm{O})$ plane are perpendicular. The disorder in the ethyl substituents is greater because they are attached on the disordered nitrogen atoms. Similar conformational disorder has been reported for a dioxane ring compound, ${ }^{21}$ where the disorder is regarded as being static because of the high energy barrier of $33.5 \mathrm{~kJ} / \mathrm{mol}$ for the inversion. In the quasi-half-chair conformation of $\mathbf{A}$ at $200 \mathrm{~K}$, the intramolecular close contact between the $\mathrm{O}$ and $\mathrm{N}$ atoms, which could be responsible for coloration of $\mathbf{1}$, is still observed; N...O: 2.909 and $2.861 \AA$.

\section{Characterization of the phase transition}

Corresponding to the change in the cell parameters shown in Figure1, the DSC analysis of $\mathbf{1}$ indicates an apparent exothermic peak top at $162.9 \mathrm{~K}$ with the onset at $163.8 \mathrm{~K}$ upon decreasing the temperature to $120 \mathrm{~K}$ and an endothermic peak top at $166.8 \mathrm{~K}$ with the onset at $165.2 \mathrm{~K}$ in the heating mode (Figure 5). Thus, the transition exhibits thermal hysteresis of $4 \mathrm{~K}$, suggesting a first-order phase transition. ${ }^{22}$ The peak profile upon cooling gives $\Delta H=2.1 \mathrm{~kJ} / \mathrm{mol}$ for $\mathbf{I} \rightarrow \mathbf{I I}$ and $\Delta H=2.0 \mathrm{~kJ} / \mathrm{mol}$ for the opposite process. The entropy change $\Delta S$ was deduced to be $12.7 \mathrm{JK}^{-1} \mathrm{~mol}^{-1}$ for $\mathbf{I} \rightarrow \mathbf{I I}$. The ratio of the numbers of distinguishable orientations for $\mathbf{I}$ is two by taking into account the two disordered sites of the quasi-half-chair conformers. Then, $\Delta S$ is estimated to be $5.76 \mathrm{JK}^{-1} \mathrm{~mol}^{-1}$ on the basis of $\Delta S=R \ln 2$. The experimentally deduced value, however, is as large as $12.7 \mathrm{JK}^{-1} \mathrm{~mol}^{-1}$, suggesting a significant contribution from external cohesive interactions and molecular vibrations.

(a)

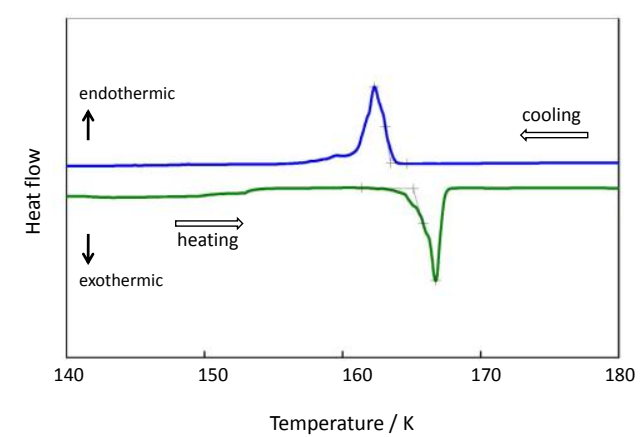

(b)

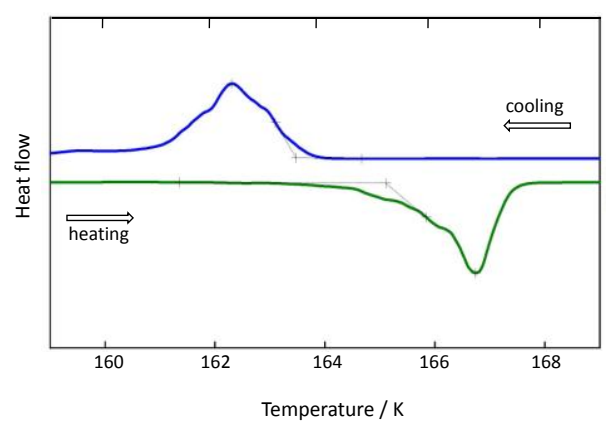


Figure 5. (a) DSC thermograms of 1 in temperature range from $-55{ }^{\circ} \mathrm{C}$ to $-150{ }^{\circ} \mathrm{C}$ at a cooling and heating rate of $2 \mathrm{~K} / \mathrm{min}$. (b) DSC profile in the vicinity of the phase transition temperature displayed by enlargement of the temperature scale, ca.5 times that of (a).

Upon decreasing the temperature from $300 \mathrm{~K}$ to $90 \mathrm{~K}$ the lattice constants of the $a$ and $b$-axes are decreased by $0.25 \AA$ and $0.66 \AA$, respectively, and consequently the unit cell volume is decreased by over $4 \%$. Thus, the densities of the crystals are 1.278 $\mathrm{g} / \mathrm{cm}^{3}$ in polymorph II at $90 \mathrm{~K}$ and $1.221 \mathrm{~g} / \mathrm{cm}^{3}$ in polymorph I at $200 \mathrm{~K}$. Compression of the unit cell parameters should be associated with intermolecular interactions. Thus, we carried out Hirshfeld surface analysis, ${ }^{23}$ which represents a unique method to explore intermolecular interactions in molecular crystals using a partitioning of crystal space in a novel visual manner. The Hirshfeld surfaces and the fingerprints of A and B molecules in I and II at $200 \mathrm{~K}$ and $90 \mathrm{~K}$, respectively, are illustrated in Figure $6 .^{24}$ The fingerprint plots are quite asymmetric, because the interactions occur between two crystallographically distinct molecules.

It can be seen from the Hirshfeld surface and the fingerprint (Figure 6) that the chemical environment of $\mathbf{A}$ is different between isostructural crystals $\mathbf{I}$ and $\mathbf{I I}$. This is also the case for $\mathbf{B}$, although the difference appears to be less pronounced than that of $\mathbf{A}$. The $\mathrm{H} \cdots \mathrm{O} / \mathrm{H} \cdots \mathrm{O}$ intermolecular interactions appear typically in $\mathbf{A}$ and $\mathbf{B}$ of $\mathbf{I I}$ as two distinct spikes close to the diagonal in their $2 \mathrm{D}$ fingerprint plots. In addition, $\mathbf{B}$ in II represents the $\mathrm{H} \cdots \mathrm{H}$ contacts by a spike on the diagonal at or shorter than the $\mathrm{H}$ atom vdW radius of $1.20 \AA$. These interactions are evident from the bright red spots in the Hirshfeld surface plots. The red spots in the Hirshfeld surface of half-chair conformer $\mathbf{B}$ in $\mathbf{I}$ and II are ascribable to the close contact of the hydrogen of the imidazolidine ring (H11A ‥H11A: $2.224 \AA$ ), which is somewhat more bright in II than in I. On the other hand, for disordered molecule $\mathbf{A}$, three prominent red spots, which result from the bifurcated contact with $\mathbf{B}$ and the interaction linking $\mathbf{A}$ molecules linearly along the $a$ axis, become much more appreciable in $\mathbf{I}$, indicating that these contacts loosen in

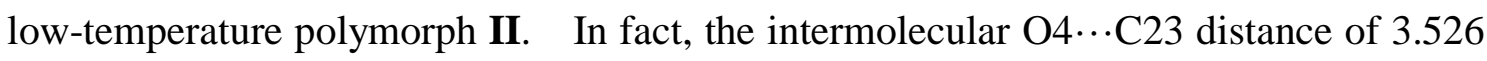
$\AA$ at $90 \mathrm{~K}$ is longer than that of $3.396 \AA$ at $200 \mathrm{~K}$ (Table 2). Temperature dependence of other intermolecular distances related to the $\mathrm{C}=\mathrm{O} \cdots \mathrm{HC}$ contacts are listed in Table 2 . These results appear to be consistent with observation that the range of values in $d_{\mathrm{e}}$ and $d_{\mathrm{i}}$ of the fingerprint plots of $\mathbf{A}$ and $\mathbf{B}$ in $\mathbf{I}$ looks more compact than that in II, suggesting that low temperature polymorph II is less dense than high temperature polymorph $\mathbf{I}$. 
Table 2. Intermolecular C---C distances related to short contacts between the carbonyl oxygen and the hydrogen in II and I.

It seems to be rather strange that the intermolecular contacts become less tight with decreasing temperatures, nevertheless the crystal density increases. It could be interpreted, however, by taking it into consideration that the decrease of the cell parameters in II is mainly attributed to reduction in the volume of $\mathbf{A}$, being caused by conformational freezing, rather than enhancement of intermolecular contacts. The molecular volumes of A and $\mathbf{B}$ in I obtained from Hirshfeld surface analysis are 346.8 $/ \AA^{3}$ and $344.3 / \AA$, respectively, while those in II are $325.3 / \AA^{3}$ and $331.7 / \AA$, indicating that $\mathbf{A}$ is significantly contracted in the low temperature phase.

The largest compression occurs along the $b$-axis, indicating a decrease in the thickness of the layer constructed from $\mathbf{A}$ molecules. As a result of conformational freezing of the imidazolidine ring in II, the intramolecular distance between the methyl carbons of the ethyl substituents in quasi-half chair conformers (Figure $3 \mathrm{a}$ and b: $\mathrm{C} 30 \cdots \mathrm{C} 30 \mathrm{i})$, which corresponds approximately to the molecular size along the $b$-axis and can be regarded as the thickness of the layer of $\mathbf{A}$ along the $b$-axis, is markedly decreased from $7.732 \AA$ at $200 \mathrm{~K}$ to $7.213 \AA$ at $90 \mathrm{~K}$. These results suggest that shrinkage of the molecules in a crystal lattice could bring about decrease of the cell parameters, even if intermolecular cohesive interactions are not enhanced. 
I (A)
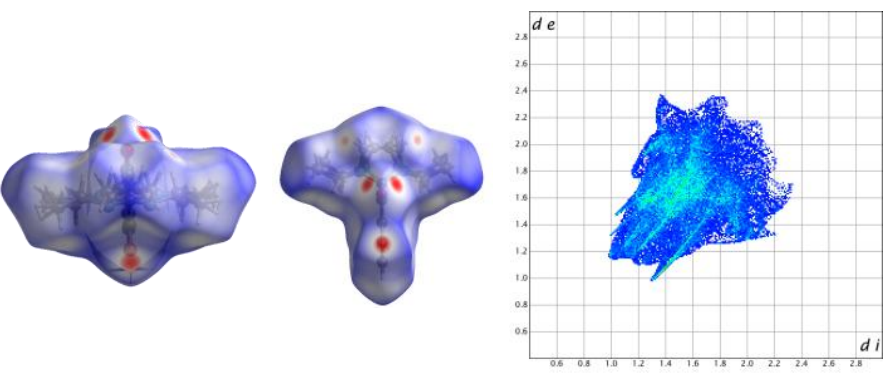

I (B)
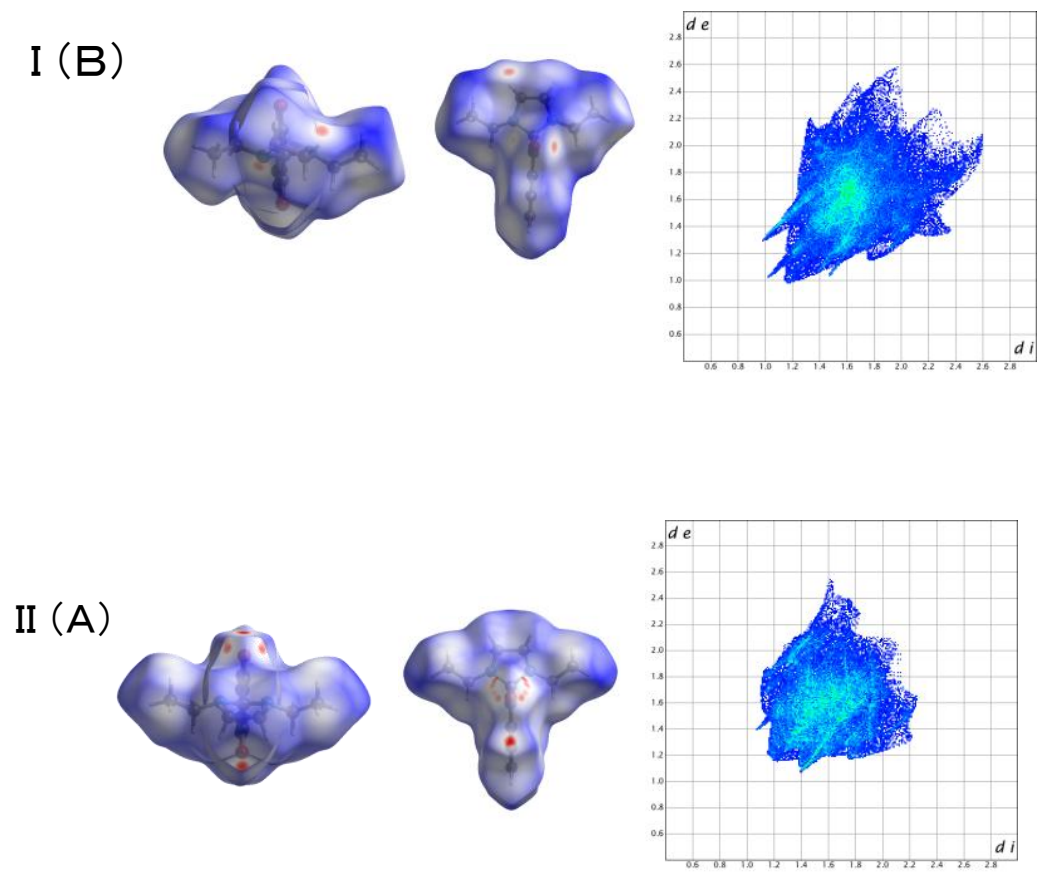

II (B)
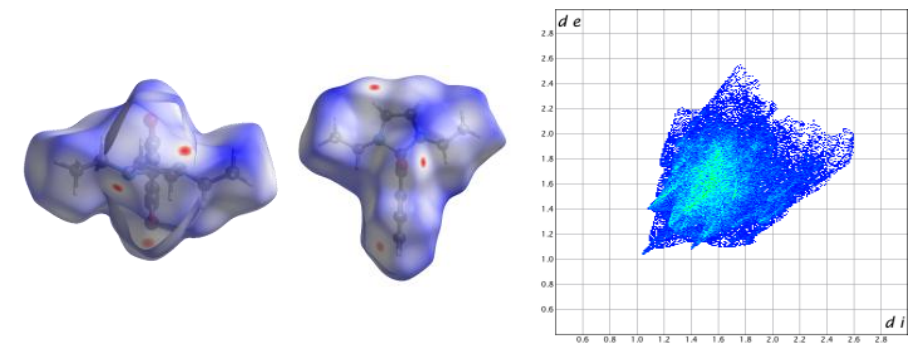

Figure 6. Left and center: Hirshfeld surface mapped over a $d_{\text {norm }}$, using a color scale of red (shorter than vdW separation), white (equal to vdW separation) and blue (longer than vdW separation) for A and B molecules in I (at $200 \mathrm{~K}$ ) and II (at 90K). Left: Projection viewed from the front (as shown in Figure 2). Center: Projection viewed from the top. Right: corresponding 2D fingerprint plots for $\mathbf{A}$ and $\mathbf{B}$ molecules in $\mathbf{I}$ (at $200 \mathrm{~K}$ ) and II (at 90K). 
The molecular structure of $\mathbf{1}$ was optimized in the gas phase and its geometrical parameters were investigated by DFT calculation at the B3LYP/6-311G(d,p) level. The envelope and half-chair structures, involved in II as conformational isomorphs $\mathbf{A}$ and $\mathbf{B}$, were obtained as optimized molecular geometries with the minimum energies, in good agreement with the geometries of $\mathbf{A}$ and $\mathbf{B}$ at $90 \mathrm{~K}$ (Table 3). The half-chair form adopts $C_{2}$ symmetry including the ethyl substituent and the torsion angle N-C-C-N of $38.71^{\circ}$ (obs; $43.6(1)^{\circ}$ ), while the envelope conformation with $C s$ symmetry is the most stable with the torsion angle N-C-C-N of $0.07^{\circ}\left(\mathrm{obs} ; 0.0(1)^{\circ}\right)$. The half-chair form is slightly more stable than the envelope form by $2.6 \mathrm{~kJ} / \mathrm{mol}$. The barrier between the half-chair and envelope conformations was calculated to be $18.5 \mathrm{~kJ} / \mathrm{mol}$. The quasi-half-chair form that appears in the dynamic disordering of $\mathbf{A}$ was not obtained as a potential-minimum conformation. Thus, the quasi-half-chair form should occur as a result of conformational adjustment. ${ }^{25}$ The dynamic motion freezes below $163 \mathrm{~K}$, indicating that the thermal energy at this temperature, i.e., $1.4 \mathrm{~kJ} / \mathrm{mol}$, approximately corresponds to the activation energy of the conformational interconversion of the quasi-half-chair conformer of A. This energy value is smaller than the calculated one, presumably indicating that $\mathbf{A}$ in polymorph $\mathbf{I}$ is conformationally adjusted and disordered at a point very close to the transition state in its gas-phase potential energy surface.

Table 3. Optimized geometries of envelope and half-chair forms of 1 in gas phase and their total energies at the B3LYP/6-311G(d,p) basis set. The observed values are given in parenthesis.

The phase transition from I to II was also monitored by temperature-dependent IR spectroscopy. In general, no substantial changes were observed in the position and peak height during the cooling of the crystalline sample of $\mathbf{1}$ except for in the spectral region assignable to the carbonyl stretching vibration, wherein an apparent spectral change was observed. With decreasing temperature, a new band, in addition to those at $1743 \mathrm{~cm}^{-1}$ and $1715 \mathrm{~cm}^{-1}$, appears as a shoulder of $1699 \mathrm{~cm}^{-1}$ and can be clearly identified at $143 \mathrm{~K}$ (Figure 7). This band disappears again upon warming to room temperature, indicating a reversible change in the molecular structure. The origin of the new band is ascribed to the envelope conformer $\mathbf{A}$ of polymorph II, which is absent above the transition temperature and is formed by freezing of the dynamic equilibrium of the quasi-half-chair form. 


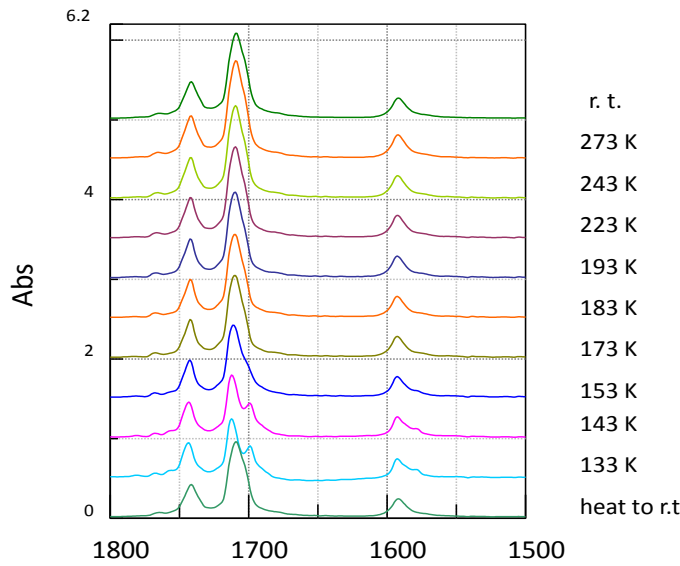

Wavenumber/cm ${ }^{-1}$

Figure 7. Changes in variable-temperature FT-IR spectra with temperature in the range of $1800-1500 \mathrm{~cm}^{-1}$.

On the basis of the optimized geometries, the vibration frequencies were calculated at the B3LYP/6-311G(d,p) level. No imaginary frequencies were observed. The calculated wavenumbers of the $\mathrm{C}=\mathrm{O}$ stretching absorption bands are $1814 \mathrm{~cm}^{-1}$ and $1783 \mathrm{~cm}^{-1}$ for the half-chair conformer of molecule $\mathbf{B}$ and $1811 \mathrm{~cm}^{-1}$ and $1761 \mathrm{~cm}^{-1}$ for the envelope conformer of molecule A (Figure 8). The symmetric stretching band has the same wavenumber for both conformers, while an antisymmetric stretching band appeared at distinct frequencies between the conformers. The frequencies observed experimentally in the crystalline phase at $143 \mathrm{~K}$ are attributed to molecules $\mathbf{A}$ and $\mathbf{B}$ with the half-chair and envelope conformations, respectively. The calculated bands are higher than those observed experimentally (Figure 8). However, by applying frequency scaling using 0.9613 as a scaling factor, ${ }^{26}$ the calculated wavenumbers show good agreement with the experimental values. Thus, upon superposing the calculated bands of both conformers, the experimental spectrum at $143 \mathrm{~K}$ was reproduced with good agreement. Thus, the $1699 \mathrm{~cm}^{-1}$ band can be confidently assigned to the $\mathrm{C}=\mathrm{O}$ stretching mode of the envelope conformer of $\mathbf{A}$. 


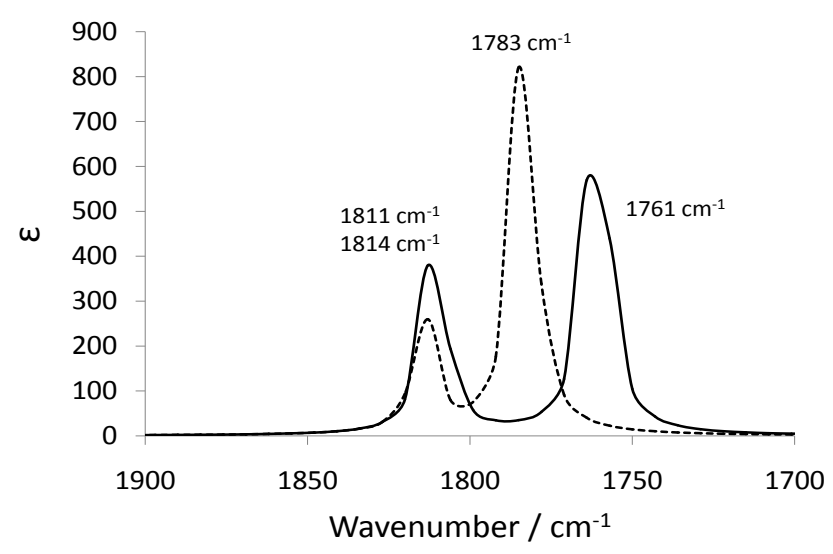

Figure 8. Calculated IR spectra of $\mathbf{1}$ in the range of the carbonyl stretching vibration. (a) - - : envelope form. (b) ----: half-chair form.

\section{Concluding Remarks}

Compound 1 exists in two conformational polymorphs, II (below $161 \mathrm{~K}$ ) and I (above $164 \mathrm{~K}$ ), each of which exhibit conformational isomorphism. The crystal structures of these polymorphs are only different in the conformation of one imidazolidine ring of the two crystallographically independent $\mathbf{1}$ molecules: in form $\mathbf{I}$, the ring is dynamically disordered by interconversion between two equivalent quasi-half-chair conformations, which are ordered to form an envelope conformation in I. There is another conformer in both I and II, that is, a half-chair conformer. Therefore, polymorphs I and II are conformational isomorphs. Polymorphs I and II have only order-disorder-level conformational differences in their crystal structure. Usually in an order-disorder transition triggered by ordering of the molecular orientation, the crystalline framework exists in the nonpolar space group at high temperatures and disordered orientations settle into a single ordered state. The phase transition of $\mathbf{1}$, however, includes no change in the space group at the order-disorder phase transition, i.e., the space group Pnma is retained after the transition, probably because settlement of the conformational motion occurs in part of the molecular framework. The transition between $\mathbf{I}$ and $\mathbf{I I}$ is referred to as isosymmetric structural phase transitions. $^{27}$

It should be noted that the dynamically disordered conformer $\mathbf{A}$ in $\mathbf{I}$ does not freeze 
to its interconverting quasi-half-chair forms but settles into an envelope conformer. The quasi-half-chair form is not an energy-minimum conformation but is in a conformationally adjusted geometry. It may be concluded that the order-disorder transition of $\mathbf{1}$ is triggered by conformational freezing of molecule $\mathbf{A}$ accompanying contraction of its molecular volume, which is to be followed by intermolecular cohesion. In the case of 1, however, such intramolecular trigger makes the intermolecular contacts rather loose, whereas it brings about a dense crystal as overall results.

Polymorphs I and II provide a peculiar example of polymorphs that are extremely close to the conformationally disordered crystals. They also indicate importance to confirm the existence of a phase transition for characterization of enantiotropic polymorphs in contrast to monotropic polymorphs, in which polymorphs show distinct melting points. Otherwise, the phase transition without change in the space group as described herein is liable to be overlooked and judged erroneously as disordered crystals.

\section{References}

1. (a) Setaka, W.: Yamaguchi, K. J. Am. Chem. Soc. 2013, 135 14560. (b) Li, S.; Luo, J.; Sun, Z.; Zhang, S.; Li, L.; Shi, X. Hong, M. Cryst. Growth Des. 2013, 13, 2675. (c) Fu, D. W.; Zhang, W.; Cai, H. L.; Zhang, Y.; Ge, J. Z.; Xiong, R. G.; Huang, S. D. J. Am. Chem. Soc. 2001, 133, 12780. (d) Yoshida, Y.; Hoshino, N.; Nakamura, T.; Akutagawa, T. CrystEngComm 2012, 14, 7458. (e) Ye, Q.; Akutagawa, T.; Hoshino, N.; Kikuchi, T.; Noro, S.; Xiong, R. G.; Nakamura, T. Cryst. Growth Des. 2011, 11, 4175. (f) Zhang, W.; Cai., Y.; Xiong, R-G.; Yoshikawa, H.; Awaga, K. Angew. Chem. Int. Ed. 2010, 49, 6608.

2. (a) Howard, J. A. K.; Sparkes, H. A. CrystEngComm 2008, 10, 502. (b) Stilinović, V.; Kaitner, B. Cryst. Growth Des. 2013, 13, 1703. (c) Budzianowski, A.; Katrusiak, A. Acta Crystallographica, B 2002, B58, 125. (d) Katrusiak, A.; Acta Crystallogr. 2000, B56, 872.

3. (a) Yasuda, N.; Uekusa, H.; Ohashi, Y. J. Mol. Struct. 2003, 647, 217. (b) Murugan, N. A. J. Chem. Phys. 2004, 123, 094508. (c) Harada, J.; Harakawa, M.; Ogawa, K. CrystEngComm 2009, 11, 638. (d) Katrusiak, A. Acta Crystallogr. 2000, B56, 872. (e) Harada, J.; Ogawa, K. J. Am. Chem. Soc. 2001, 123, 10884. (f) Delaney, S. P.; Pan, D.; Galella, M.; Yin, S. X.; Korter, T. M. Cryst. Growth Des. 2012, 12, 5017. (g) Harada, J.; Ogawa, K. J. Am. Chem. Soc. 2004, 126, 3539. (h) Wolak, J. E.; Knutson, J.; Martin, J. D.; Boyle, P.; Sargent, A. L.; White, J. L. J. Phys. Chem. B 
2003, 107, 13293. (i) Facey, G. A.; Connolly, T. J.; Bensimon, C.; Durst, T. Canad. J. Chem. 1996, 74, 1844.

4. In the phase transition of biphenyl, the conformational change of the molecule allows the change in the whole molecular structure. The phase transition of biphenyl and its family has been investigated in detail. For example, see: (a) Saito, K.; Yamamura, H.; Saitoh, H.; Matsuyama, K.; Kikuchi, K.; Ikemoto, I. Solid State Commun. 1994, 92, 495. (b) Lenstra, A. T. H.; Van Alsenoy, C.; Verhulst, K.; Geise, H. J. Acta Crystallogr. 1994, B50, 96.

5. Cairns, A. B.; Goodwin, A. L. Chem. Soc. Rev. 2013, 42, 4881.

6. (a) Cruz-Cabera, A.; Bernstein, J. Chem. Rev. 2014, 114, 2170. (b) Bernstein, J.; Polymorphism in Molecular Crystals; Oxford University Press: New York, 2002. (c) Threlfall, T. L. Analyst 1995, 120, 2435.

7. (a) Brittain, H. D. Methods for the Characterization of Polymorphs and Solvates in Polymorphism in Pharmaceutical Solids, ed. by Brittain, H. G., Marcel Dekker, Inc., New York, 1999, pp.227-278. (b) Burger, A.; Ramberger, R. Microchim. Acta 1979, 2, 259. (c) Burger, A.; Ramberger, R. Microchim Acta 1979, 2, 273. (d) Giron, D. Thermochimica Acta 1995, 248, 1.

8. For references related to the issues of the borderline of polymorphs and molecular disorder or their origins, see (a) Vujovic, D.; Nassimbeni, L. R. Cryst. Growth Des. 2006, 6, 1595. (b) Threlfall, T. L.; Gelbrich, T. Cryst. Growth. Des. 2007, 7, 2297. (c) Skořepová, E.; Čejka, J.; Hušák, M.; Eigner, V.; Rohlíček, J.; Šturc, A.; Kratochvíl. B. Cryst. Growth Des. 2013, 13, 5193. (d) Borodi, G.; Pop, M.M.; Onija, O.; Filip, X. Cryst. Growth. Des. 2012, 12, 5846. (e) Chopra, D.; Row, T. N. G.; Cryst. Growth Des. 2008, 8, 848. (f) Delaney, S. P.; Pan, D.; Galella, M.; Yin, S. X.; Korter, T. M. Cryst. Growth Des. 2012, 12, 5017. (g) Copley, R. C. B.; Barnett, S. A.; Karamertzanis, P. G.; Harris, K. D. M.; Kariuki, B. M.; Xu, M.; Nickels, A.; Lancaster, R. W.; Price, S. L. Cryst. Growth Des. 2008, 8, 3474. (i) Dikundwar. A. G.; Pete, U. D.: Zada, C. M.; Bendre, R. S. Cryst. Growth Des. 2012, 12, 4530.

9. (a) Schönberg, A.; Singer, E.; Eschenhof, B.; Hoyer, G. A. Chem. Ber. 1978, 111, 3058. (b) Schönberg, A; Singer, E; Osch. M.; Hoyer, G. A., Tetrahedron Lett. 1975, 37, 3217.

10. (a) Saragi, T. P. I.; Spehr, T.; Siebert, A.; Fuhrmann-Lieker, T.; Salbeck, J. Chem. Rev. 2007, 107, 1011. (b) Maslak, P. Adv. Mater. 1994, 6, 405. (c) Simmoms, H. E.; Fukunaga, T. J. Am. Chem. Soc. 1967, 89, 5208. (d) Minkin, V. Chem. Rev. 2004, 104, 2751. (e) Maslak, P.; Chopra, A.; Moylan, C. R.; 
Wortmann, R.; Lebus, S.; Rheingold, A. L.; Yap, G. P. A. J. Am. Chem. Soc. 1996, $118,1471$.

11. Sheldrick, W. S.; Schönberg, A; Singer, E. Acta Crystallogr. 1982, B38, 1355.

12. Sheldrick, G. Acta Crystallogr. 2008, A64, 112.

13. Wolff, S. K.; Girmwood, D. J.; McKinnon, J. J.; Tuner, M. J.; Jayatilaka, D.; Spackman, M. A. CrystalExplorer; University of Western Australia: Crawley, Australia, 2012.

14. McKinnon, J. J.; Jayatilaka, D.; Spackman, M. A. Chem. Commun. 2007, 3814.

15. (a) Ohtawara, K.; Teramae, H. Chem. Phys. Lett. 2004, 390, 84. (b) H. Teramae, H.; Ohtawara, K.; Ishimoto, T.; Nagashima, U. Bull. Chem. Soc. Jpn. 2008, 81, 1094. (c) Teramae, H.; Ishimoto, T.; Nagashima, U. Theoret. Chem. Acc. 2011, 130, 671.

16. Peng, C.; Schlegel, H. B. Israel J. of Chem., 1993, 33, 449.

17. Peng, C.; Ayala, P. Y.; Schlegel, H. B.; Frisch, M. J. J. Comp. Chem. 1996, 17, 49.

18. Gaussian 09, Revision D.01, Frisch, M. J.; Trucks, G. W.; Schlegel, H. B.; Scuseria, G. E.; Robb, M. A.; Cheeseman, J. R.; Scalmani, G.; Barone, V.; Mennucci, B.; Petersson, G. A.; Nakatsuji, H.; Caricato, M.; Li, X.; Hratchian, H. P.; Izmaylov, A. F.; Bloino, J.; Zheng, G.; Sonnenberg, J. L.; Hada, M.; Ehara, M.; Toyota, K.; Fukuda, R.; Hasegawa, J.; Ishida, M.; Nakajima, T.; Honda, Y.; Kitao, O.; Nakai, H.; Vreven, T.; Montgomery, Jr., J. A.; Peralta, J. E.; Ogliaro, F.; Bearpark, M.; Heyd, J. J.; Brothers, E.; Kudin, K. N.; Staroverov, V. N.; Kobayashi, R.; Normand, J.; Raghavachari, K.; Rendell, A.; Burant, J. C.; Iyengar, S. S.; Tomasi, J.; Cossi, M.; Rega, N.; Millam, J. M.; Klene, M.; Knox, J. E.; Cross, J. B.; Bakken, V.; Adamo, C.; Jaramillo, J.; Gomperts, R.; Stratmann, R. E.; Yazyev, O.; Austin, A. J.; Cammi, R.; Pomelli, C.; Ochterski, J. W.; Martin, R. L.; Morokuma, K.; Zakrzewski, V. G.; Voth, G. A.; Salvador, P.; Dannenberg, J. J.; Dapprich, S.; Daniels, A. D.; Farkas, Ö,; Foresman, J. B.; Ortiz, J. V.; Cioslowski, J.; Fox, D. J. Gaussian, Inc., Wallingford CT, 2009.

19. (a) Bilton, C.; Howard, J. A. K.; Laxmi Madhavi, N. N.; Nangia, A.; Desiraju, G. R.; Allenc, F. H.; Wilson, C. C. Chem. Commun. 1999, 26, 1675. (b) Nangia, A. Acc. Chem. Res. 2008, 41, 595. (c) de Castro, R. A. E.; Canotilho, J.; Barbosa, R. M.; Silva, M. R.; Beja, A. M.; Paixao, J. A.; Redinha, J. S. Cryst. Gwowth Des. 2007, 7, 496. (d) Maria, T. M. R.; Ricardo, R. A. E.; Bebiano, S. S.; Silva, M. R.; Beja, A. M.; Canotilho, J.; Eusebio, M. E. S. Cryst. Growth Des. 2010, 10, 1194. (e) Bis, J. A.; Vishweshwar, P.; Middleton, R. A.; Zaworotko, M. Cryst. 
Growth Des. 2006, 6, 1048. (f) Kumar, V. S. S.; Addlagatta, A.; Nangia, A.; Robinson, W. T.; Broder, C. K.; Mondal, R.; Evans, I. R.; Howard, J. A. K.; Allen, F. H. Angew. Chem. Int. Ed. 2002, 41, 3848.

20. In DSC analysis, the transition was observed at $164 \mathrm{~K}-161 \mathrm{~K}$ during the cooling process, whereas in X-ray analysis the reversible change of the lattice constants occurred at 158-153 K. This inconsistency may arise from difference in cooling rates or particle size used in measurements. In order to determine the crystal structure at the temperature as close as possible to the transition temperature, we repeated the X-ray crystallographic analysis at $153 \mathrm{~K}$ and $163 \mathrm{~K}$ by collecting diffraction data on a Rigaku RAXIS RAPID imaging plate area detector. The results at $153 \mathrm{~K}$ and $163 \mathrm{~K}$ are consistent with those obtained for II and I, respectively. Crystal data and structure refinement are summarized in Table S4.

21. Molčanov, K.; Stolić, I.; Kovačević, G.; Kojić-Prodić, B.; Bajić, M. J. Mol. Struct. 2011, 987, 174.

22. Blundell, S. J.; Katherine, M. Concepts in Thermal Physics; Oxford University Press: New York, 2008.

23. (a) Spackman, M. A.; McKinnon, J. J.; CrystEngComm. 2002, 4, 378. (b) Spackman, M. A. Phys. Scr. 2013, 87, 048103. (c) Spackman, M. A.; Jayatilaka, D. CrystEngComm 2009, 11, 19.

24. The Hirshfeld surfaces and the fingerprints of $\mathbf{A}$ and $\mathbf{B}$ molecules at $120 \mathrm{~K}$ in II and at $160 \mathrm{~K}$ in $\mathbf{I}$ are depicted in Figure S4 together with those at $90 \mathrm{~K}$ and $200 \mathrm{~K}$ for comparison. The views at $120 \mathrm{~K}$ and $160 \mathrm{~K}$ are almost identical with those at $90 \mathrm{~K}$ and $200 \mathrm{~K}$, respectively.

25. Cruz-Cabeza, A. J.; Bernstein, J. Chem. Rev. 2014, 114, 2170.

26. Scott, A. P.; Radom, L. J. Phys. Chem. 1996, 100, 16502.

27. (a) Cai, W.; Katrusiak, A. Nature Comm. 2014, 5, article number 4337. (b) Christy, A. G. Acta Cryst. B 51, 1995, 753. 
Table 1. Crystal data and structure refinement for 1 at $90 \mathrm{~K}, 120 \mathrm{~K}, 160 \mathrm{~K}$, and $200 \mathrm{~K}$.

\begin{tabular}{|c|c|c|c|c|}
\hline & $90 \mathrm{~K}$ & $120 \mathrm{~K}$ & $160 \mathrm{~K}$ & $200 \mathrm{~K}$ \\
\hline polymorph & II & II & $\mathbf{I}$ & $\mathbf{I}$ \\
\hline empirical formula & $\mathrm{C}_{22.5} \mathrm{H}_{27} \mathrm{~N}_{3} \mathrm{O}_{3}$ & $\mathrm{C}_{22 \cdot 5} \mathrm{H}_{27} \mathrm{~N}_{3} \mathrm{O}_{3}$ & $\mathrm{C}_{22 \cdot 5} \mathrm{H}_{27} \mathrm{~N}_{3} \mathrm{O}_{3}$ & $\mathrm{C}_{22.5} \mathrm{H}_{27} \mathrm{~N}_{3} \mathrm{O}_{3}$ \\
\hline formula weight & 387.47 & 387.47 & 387.47 & 387.47 \\
\hline crystal size/ mm & $0.310 \times 0.203 \times 0.097$ & $0.522 \times 0.382 \times 0.272$ & $0.522 \times 0.382 \times 0.272$ & $0.522 \times 0.382 \times 0.272$ \\
\hline crystal system & orthorhombic & orthorhombic & orthorhombic & orthorhombic \\
\hline space group & Pnma (\#62) & Pnma (\#62) & Pnma (\#62) & Pnma (\#62) \\
\hline$a / \AA$ & $15.1342(4)$ & $15.1497(4)$ & $15.3000(4)$ & $15.3886(8)$ \\
\hline$b / \AA$ & $28.3983(7)$ & $28.4586(8)$ & $28.9002(7)$ & $29.0676(15)$ \\
\hline$c / \AA$ & $9.3718(3)$ & $9.3889(2)$ & $9.3993(2)$ & $9.4210(5)$ \\
\hline$V / \AA^{3}$ & $4027.86(19)$ & $4047.92(18)$ & $4156.12(17)$ & 4214.1(4) \\
\hline$Z$ & 8 & 8 & 8 & 8 \\
\hline$r_{\text {calcd }} / \mathrm{gcm}^{-3}$ & 1.278 & 1.272 & 1.238 & 1.221 \\
\hline GOF on $F^{2}$ & 1.022 & 1.079 & 1.042 & 1.041 \\
\hline \multirow[t]{2}{*}{$R[I>2 s(I)]$} & $R_{1}=0.0410$ & $R_{1}=0.0411$ & $R_{1}=0.0599$ & $R_{1}=0.0694$ \\
\hline & $w R_{2}=0.1018$ & $w R_{2}=0.1181$ & $w R_{2}=0.1645$ & $w R_{2}=0.2048$ \\
\hline \multirow[t]{2}{*}{$R($ all data $)$} & $R_{1}=0.0523$ & $R_{1}=0.0462$ & $R_{1}=0.0799$ & $R_{1}=0.0838$ \\
\hline & $w R_{2}=0.1094$ & $w R_{2}=0.1229$ & $w R_{2}=0.1799$ & $w R_{2}=0.2206$ \\
\hline $\mathrm{CCDC}$ & 1007726 & 1007727 & 1025767 & 1007729 \\
\hline
\end{tabular}


Table 2. Intermolecular C … C distances related to short contacts between the carbonyl oxygen and the hydrogen in I and II.

\begin{tabular}{lcc}
\hline \multicolumn{1}{c}{ polymorph } & II & I \\
\hline \multicolumn{1}{c}{ temperature } & $90 \mathrm{~K}$ & $200 \mathrm{~K}$ \\
\hline $\mathrm{O} 4 \cdots \mathrm{H} 23-\mathrm{C} 23$ / $\mathrm{A}$ & 3.526 & 3.396 \\
$\mathrm{O} 4 \cdots \mathrm{H} 6-\mathrm{C} 6$ & 3.511 & 3.392 \\
$\mathrm{O} 3 \cdots \mathrm{H} 6-\mathrm{C} 6$ & 3.196 & 3.535 \\
$\mathrm{O} 3 \cdots \mathrm{H} 5-\mathrm{C} 5$ & 3.164 & 3.156 \\
& & \\
$\mathrm{O} 1 \cdots \mathrm{H} 10-\mathrm{C} 10$ & 3.386 & 3.411 \\
$\mathrm{O} 1 \cdots \mathrm{H} 15-\mathrm{C} 15$ & 3.478 & 3.447 \\
$\mathrm{O} 2 \cdots \mathrm{H} 7-\mathrm{C} 7$ & 3.146 & 3.222 \\
& & \\
\hline
\end{tabular}


Table 3. Optimized geometries of envelope and half-chair forms of $\mathbf{1}$ in gas phase and their total energies at the B3LYP/6-311G(d,p) basis set. The observed values are given in parenthesis.

\begin{tabular}{|c|c|c|c|c|c|}
\hline form & $\begin{array}{c}\mathrm{N}-\mathrm{C}-\mathrm{C}-\mathrm{N} \\
/ \mathrm{O}\end{array}$ & $\begin{array}{c}\mathrm{CEt}-\mathrm{C}-\mathrm{N}-\mathrm{C}_{\text {spiro }} \\
/ \mathrm{O}\end{array}$ & $\begin{array}{c}\mathrm{CEt}-\mathrm{C}-\mathrm{N}-\mathrm{C}_{\text {spiro }} \\
/ \mathrm{O}\end{array}$ & $\begin{array}{l}\text { total energy } \\
\text { /a.u. }\end{array}$ & $\begin{array}{l}\text { relative } \\
\text { energy } \\
/ \mathrm{kJmol}^{-1}\end{array}$ \\
\hline half-chair & $\begin{array}{l}-38.71 \\
(43.57)\end{array}$ & $\begin{array}{l}-160.03 \\
(166.31)\end{array}$ & $\begin{array}{l}-160.03 \\
(161.38)\end{array}$ & -842.5877238 & 0.0 \\
\hline envelope & $\begin{array}{l}0.07 \\
(0.00)\end{array}$ & $\begin{array}{l}162.92 \\
(164.00)\end{array}$ & $\begin{array}{l}-162.88 \\
(164.00)\end{array}$ & -842.5867418 & 2.6 \\
\hline transition state & -36.53 & -139.21 & 146.25 & -842.5806681 & 18.5 \\
\hline
\end{tabular}

